INDEPENDENT JOURNAL OF MANAGEMENT \& PRODUCTION (IJM\&P) http://www.ijmp.jor.br

v. 12, n. 7, September-October 2021

ISSN: 2236-269X

DOI: $10.14807 /$ ijmp.v12i7.1468

\title{
COMPARATIVE ANALYSIS OF THE TODIM METHOD ADHERENCE TO PROSPECT THEORY
}

\author{
Alexandre Leoneti \\ University of Sao Paulo, Brazil \\ E-mail: ableoneti@usp.br \\ Luiz Flávio Autran Monteiro Gomes \\ Ibmec/RJ, Brazil \\ E-mail: luiz.gomes@professores.ibmec.edu.br
}

Submission: 10/19/2020

Accept: 11/11/2020

\section{ABSTRACT}

Prospect Theory provides a broad and solid frame of reference for modeling the decision making of rational agents. In the early 1990s, the structure of Prospect Theory was used to propose a method to aid a multicriteria decision based on the process of paired comparison. The research reported in this article has empirically assessed the adherence of the mathematical model of the original TODIM method, together with its variations available in the literature, to Prospect Theory and compared them with a multicriteria method that does not use that theory. From a comparative analysis, it was realized that the different variations of the TODIM method regarding the incorporation of Prospect Theory's rationality within the context of Multicriteria Decision Aid still do not bring the benefits of an already consolidated theory to the context of decisionmaking aid. Thus, it is suggested that further studies be conducted to improve the adherence of Prospect Theory within the structure of the TODIM method, so that the benefits of a consolidated theory of decision lead to better results, notably from the perspective of using the method for the purposes of forecast.

Keywords: TODIM; Prospect Theory; Multicriteria Decision Aid; Risk Aversion 
ISSN: $2236-269 X$

DOI: 10.14807/ijmp.v12i7.1468

\section{INTRODUCTION}

Having its roots in early writings of Enlightenment philosophers, Expected Utility Theory was by far the dominating paradigm for analyzing human decision making until the 70’s (Mongin \& Baccelli, 2020; Lengwiler, 2009). That theory classifies the attitudes of humans facing risky choices as being of risk aversion, risk proneness, or risk neutrality (Benjamin, Fontana \& Kimball, 2020; Breig \& Feldman, 2020).

In the 70's, however, from empirical analyzes of how agents make decisions, Daniel Kahneman and Amos Tversky found that the measures of satisfaction associated with the same physical magnitude are not absolute, but relative, depending on the situation of gain or loss (Kahneman \& Tversky, 1979).

Specifically, the authors found that the same magnitude will cause disproportionate displacements depending on their previous reference point, being: (i) that it will occur similarly to the modern utility theory when the displacement is identified as gain; and (ii) that an amplification parameter must be associated for when the displacement is identified as a loss.

This amplification parameter was later determined empirically by Tversky and Kahneman (1992) at a value of 2.25. It is noted that the main contribution of those authors was the proposition of the perspective of the decision agent regarding the points of reference to the previous state regarding which gains and losses are evaluated, this being called Prospect Theory. Prospect Theory is today, notably under the formulation of Cumulative Prospect Theory, one of the most complete structures for modeling the decision-making of rational agents (Eisenführ, Weber \& Langer, 2010).

In the early 1990s, Gomes and Lima (1991, 1992) used the structure of Prospect Theory to propose a multicriteria decision-making method based on the paired comparison process, which is recurrent in the multicriteria method structure. The method was named TODIM (acronym for TOmada de Decisão Interativa e Multicritério, in Portuguese). In TODIM, it was proposed to apply the concept of Prospect Theory using a conditional function for the pairwise comparison process between alternatives for each criterion being evaluated. This conditional function was identified by the Greek letter $\varphi(\mathrm{Phi})$.

The square root structure used in the TODIM method can be considered a particular case of the structure proposed in Tversky and Kahneman (1992) when considering the value $\alpha$ $=\beta=0.5$. Thus, since its proposition, variations of the Phi function of the TODIM method have 
DOI: 10.14807/ijmp.v12i7.1468

been suggested in order to optimize the adherence of its mathematical model with Prospect Theory.

According to Yoon and Hwang (1995) the adherence of the mathematical model is "how well a method predicts decisions made without any assistance regardless of the judgments used to adjust the model". In this sense, it is possible to find in the literature the contributions of Gomes and González (2012), Lourenzutti and Krohling (2013), and Llamazares (2018).

The present research intends to empirically evaluate the adherence of the mathematical model of the original TODIM method, together with its variations available in the literature, to Prospect Theory and to compare them with a multicriteria method that does not use this theory. For this, the data from the experiment presented in Leoneti (2016) were used as input data for the comparison of these methods.

Furthermore, from the results of the study, the TOPSIS method (Technique for Order Preference by Similarity to Ideal Solution) (Yoon \& Hwang, 1995), was therefore selected according to Leoneti (2016), because when considering the number of matches of the method with the surveyed decision makers, the best scores were achieved by the TOPSIS method, including the 15 times the method correctly identified the first alternative in the decision makers' preference, which meant $79 \%$ accuracy.

The next section details the chosen methods, the results of which are presented and discussed in the subsequent section.

\section{RESEARCH FRAMEWORK}

\subsection{Topsis}

The TOPSIS method was proposed in Yoon and Hwang (1995) and several studies have applied it for aiding decision-making processes for a quite wide range of situations. In the context of the COVID-19 pandemic, Majumder, Biswas, and Majumder (2020) applied the TOPSIS method for identifying risk factors and continuous monitoring of death of COVID-19. Similarly, Mahmudova (2020) applied the TOPSIS method for improving software efficiency through the optimization of management process. In its turn, Dehdasht et al. (2020) used an adapted version of the TOPSIS method to select key drivers for a successful and sustainable lean construction implementation.

The key highlight of TOPSIS is its structure based on the comparison of alternatives within the Euclidean space. The method was developed based on the concept that the best 
DOI: 10.14807/ijmp.v12i7.1468

alternative must be closer to the ideal alternative and have the greatest distance from the negative solution in a geometric sense. The ideal positive and negative solutions are basically the solutions composed, respectively, by the best and worst scores of each criterion for each alternative.

Thus, the order of preference for the alternatives is produced by comparing Euclidean distances. According to the creators of TOPSIS, this method defines an index of similarity (or relative proximity) for the ideal positive solution and dissimilarity (or relative distance) of the ideal negative solution. The steps of the TOPSIS method are detailed below.

Step 1: standardize the criteria using a standardization vector presented in (1):

$$
r_{i j}=\frac{x_{i j}}{\sqrt{\sum_{i=1}^{m} x_{i j}^{2}}}, i=1, \ldots, m ; j=1, \ldots, n
$$

Step 2: calculate the standardized values according to (2):

$$
v_{i j}=w_{j} r_{i j}, i=1, \ldots, m ; j=1, \ldots, n
$$

where $w_{j}$ is the weight value of the $\mathrm{j}^{\text {th }}$ criterion.

Step 3: identify the ideal positive and negative solutions according to (3):

$$
\begin{aligned}
& I^{+}=\left\{v_{1}^{+}, v_{2}^{+}, \ldots, v_{j}^{+}, \ldots v_{n-1}^{+}, v_{n}^{+}\right\}=\left\{\left(\max _{i} v_{i j} \mid j \in B\right),\left(\min _{i} v_{i j} \mid j \in C\right)\right\} \\
& I^{-}=\left\{v_{1}^{-}, v_{2}^{-}, \ldots, v_{j}^{-}, \ldots v_{n-1}^{-}, v_{n}^{-}\right\}=\left\{\left(\min _{i} v_{i j} \mid j \in B\right),\left(\max _{i} v_{i j} \mid j \in C\right)\right\}
\end{aligned}
$$

where $B$ is the set of benefit criteria, where the preferable value is greater, and $C$ is the set of cost criteria, where the preferable value is less.

Step 4: calculate the distance measurements for the ideal positive and negative alternatives for (3) and (4):

$$
\begin{aligned}
& D_{i}^{+}=\sqrt{\sum_{j=1}^{n}\left(v_{i j}-v_{j}^{+}\right)^{2}}, i=1, \ldots, m \\
& D_{i}^{-}=\sqrt{\sum_{j=1}^{n}\left(v_{i j}-v_{j}^{-}\right)^{2}}, i=1, \ldots, m
\end{aligned}
$$

Step 5: calculate the agreement rates for the alternatives using the formula in (5): 
ISSN: 2236-269X

DOI: 10.14807/ijmp.v12i7.1468

$$
C_{i}=\frac{D_{i}^{-}}{\left(D_{i}^{+}+D_{i}^{-}\right)}, i=1, \ldots, m
$$

Step 6: order the alternatives according to the $C_{i}$ indexes.

\subsection{TODIM}

TODIM is a discrete multicriteria method inspired by Prospect Theory (Kahneman \& Tversky, 1979) and was originally presented by Gomes and Lima (1991; 1992). As a decision aiding method, the number of applications of TODIM as well of some of its extensions has been significantly increasing in the last ten years. More recently, Lu, Gao and Zhao (2020) used TODIM for assessing possible environmental impacts of a pumped hydro energy storage plant. Zindani, Maity and Bhowmik (2020), used TODIM with fuzzy numbers for providing a version of that method for group decision making process. Irvanizam et al. (2020) used an extended version of TODIM with fuzzy numbers for solving the problem under dualconnection numbers.

While practically all other multicriteria methods start from the premise that the decision maker always decides seeking the solution corresponding to the maximum of some global measure of value, the TODIM method makes use of the notion of a global measure of value calculable by applying the paradigm in which consists of Prospect Theory, in which there is a relative difference between gains and losses.

With this, the method is based on a description, supported by empirical evidence, of how rational agents effectively decide in the face of risk. In order to be able to apply the Prospect Theory paradigm to a database derived from calculations and value judgments, the TODIM method builds the additive difference function (Phi function) starting from a projection of the differences between the values of any two alternatives (perceived in relation to each criterion) on a referential criterion or reference criterion (pairwise comparison). The concept of additive difference function employed by the TODIM method is based on Tversky (1969) research on the analytical treatment of the multidimensionality of a value function. The steps of the TODIM method are further detailed below.

Step 1: standardize the criteria using the sum of the values per criterion in (6):

$$
r_{i j}=\frac{x_{i j}}{\sum_{i=1}^{m} x_{i j}}, i=1, \ldots, m ; j=1, \ldots, n
$$

Step 2: calculate the Phi function in (7) for each criterion $j=1, \ldots, n$ in the pairwise comparisons between the alternatives $i=1, \ldots, m$ and $k=1, \ldots, m$ : 
DOI: $10.14807 /$ ijmp.v12i7.1468

$$
\varphi_{j}\left(x_{i}, x_{k}\right)= \begin{cases}\sqrt{\frac{w_{r}\left(x_{i j}-x_{k j}\right)}{\sum_{r=1}^{m} w_{r}}} & \text { se }\left(x_{i j}-x_{k j}\right)>0 \\ 0 & \text { se }\left(x_{i j}-x_{k j}\right)=0 \\ \frac{-1}{\theta} \sqrt{\frac{\left(\sum_{r=1}^{m} w_{c r}\right)\left(x_{k j}-x_{i j}\right)}{w_{r}}} & \text { se }\left(x_{i j}-x_{k j}\right)<0\end{cases}
$$

for $\forall(i, k)$ where $w_{r}$ is the weight of criterion $r=1, \ldots, n$ relativized by the criterion of greatest importance among the $n$ criteria in the form $w_{r}=\frac{w_{j}}{\max w_{j}}$

Step 3: determine the dominance ratio (cost and benefit) expressed in (8):

$$
\delta\left(x_{i}, x_{k}\right)=\sum_{j=1}^{n} \varphi_{j}\left(x_{i}, x_{k}\right)
$$

Step 4: calculate the performance of each alternative based on the sum of the dominance ratio and standardize the values between zero and 1.0:

$$
\xi_{i}=\frac{\sum_{k=1}^{m} \delta\left(x_{i}, x_{k}\right)-\min \sum_{k=1}^{m} \delta\left(x_{i}, x_{k}\right)}{\max \sum_{k=1}^{m} \delta\left(x_{i}, x_{k}\right)-\min \sum_{k=1}^{m} \delta\left(x_{i}, x_{k}\right)}
$$

Step 5: order the alternatives according to the values $\xi_{i}$.

\subsection{Adaptations in the Phi Function of TODIM}

The original conception of the TODIM method was adapted by different researchers to better adjust the mathematical structure of the TODIM method to the principles of Prospect Theory. In this sense, the works of Gomes and González (2012), Lourenzutti and Krohling (2013), Lee and Shih (2016), and Llamazares (2018) are available in the literature. In Gomes and González (2012), the authors proposed redefining the Phi function of the original TODIM method to allow adherence to the Cumulative Prospect Theory (CPT), as presented in Tversky and Kahneman (1992). In this sense, the authors proposed the changes presented in equation (1), so that it was a substitute for Equation 7 of the original TODIM method:

$$
\varphi_{j}\left(x_{i}, x_{k}\right)= \begin{cases}{\left[\frac{w_{r}\left(x_{i j}-x_{k j}\right)}{\sum_{r=1}^{m} w_{r}}\right]^{\alpha}} & s e\left(x_{i j}-x_{k j}\right)>0 \\ 0 & s e\left(x_{i j}-x_{k j}\right)=0 \\ -\lambda\left[\frac{\left(\sum_{r=1}^{m} w_{c r}\right)\left(x_{k j}-x_{i j}\right)}{w_{r}}\right]^{\beta} & s e\left(x_{i j}-x_{k j}\right)<0\end{cases}
$$


ISSN: 2236-269X

DOI: 10.14807/ijmp.v12i7.1468

having adopted the same values for parameters $\lambda$ and $\alpha$ as suggested in Tversky and Kahneman (1992), respectively as $\alpha=\beta=0.5$ e $\lambda=\frac{1}{\theta}$.

Lourenzutti and Krohling (2013) proposed a generalization of the TODIM method to deal with diffuse intuitionist numbers in order to make the method capable of considering random vectors that affect the performance of the alternatives. To achieve the objective, the authors identified the need for an adjustment in the Phi function of the original TODIM method, specifically in the relativization included in the Phi function of the original method, as can be seen in Equation 7. Thus, the authors proposed the adaptation of the Phi function of the TODIM method according to equation (11):

$$
\varphi_{j}\left(x_{i}, x_{k}\right)= \begin{cases}\sqrt{w_{j}\left(x_{i j}-x_{k j}\right)} & \text { se }\left(x_{i j}-x_{k j}\right)>0 \\ 0 & \text { se }\left(x_{i j}-x_{k j}\right)=0 \\ \frac{-1}{\theta} \sqrt{w_{j}\left(x_{k j}-x_{i j}\right)} & \text { se }\left(x_{i j}-x_{k j}\right)<0\end{cases}
$$

where the relative value of the criterion $w_{r}=\frac{w_{j}}{\max w_{j}}$ is replaced by its original value $w_{j}$.

Finally, Llamazares (2018) proposed the generalization of the TODIM method with the establishment of conditions under which the paradoxes related to the relativization of weights in the original Phi equation could be minimized. The author then described the Phi equations previously presented in the literature as particular cases, including those by Gomes and González (2012) and Lourenzutti and Krohling (2013). In particular, the author also presents the proposals of Lee and Shih (2016), according to equation (12):

$$
\varphi_{j}\left(x_{i}, x_{k}\right)= \begin{cases}{\left[w_{j}\left(x_{i j}-x_{k j}\right)\right]^{\alpha}} & \text { se }\left(x_{i j}-x_{k j}\right)>0 \\ 0 & \text { se }\left(x_{i j}-x_{k j}\right)=0 \\ -\lambda\left[w_{j}\left(x_{k j}-x_{i j}\right)\right]^{\beta} & \text { se }\left(x_{i j}-x_{k j}\right)<0\end{cases}
$$

where $\alpha=\beta=0.88$ and $\lambda=2.25$, and also a proposal proclaimed as the most aligned with the principles of Prospect Theory, from equation (13):

$$
\varphi_{j}\left(x_{i}, x_{k}\right)= \begin{cases}w_{j}\left(x_{i j}-x_{k j}\right)^{\alpha} & \text { se }\left(x_{i j}-x_{k j}\right)>0 \\ 0 & \text { se }\left(x_{i j}-x_{k j}\right)=0 \\ -\lambda w_{j}\left(x_{k j}-x_{i j}\right)^{\beta} & \text { se }\left(x_{i j}-x_{k j}\right)<0\end{cases}
$$

where the criteria weights are not included in the main structure of the value function proposed in Kahneman and Tversky (1979). 
ISSN: 2236-269X

DOI: 10.14807/ijmp.v12i7.1468

\section{METHODOLOGY}

To assess the adherence of the different mathematical models of the Phi function of the TODIM method available in the literature to Prospect Theory, and to compare them with a multicriteria method that does not use this theory, a Microsoft Excel ${ }^{\circledR}$ spreadsheet environment was used. In this spreadsheet, the steps described for the application of the TOPSIS method and the TODIM method were programmed, with their respective variations, namely: (i) original TODIM (Gomes \& Lima, 1991; Gomes \& Lima, 1992); (ii) TODIM-CPT (Gomes \& González, 2012); (iii) generalized TODIM I (Lourenzutti \& Krohling, 2013); (iv) generalized TODIM II (Lee \& Shih, 2016); and (v) generalized TODIM III (Llamazares, 2018). For all models, the parameter values of the mathematical models were defined as proposed in Tversky and Kahnemann (1992), where $\alpha=\beta=0.88$ and $\theta=2.25$.

As an input for this comparison, an experiment previously presented in Leoneti (2016) was used, with the participation of twenty students from different years and courses from the Ribeirão Preto School of Economics, Administration and Accounting. Those twenty students were selected because they were taking a course on decision making in organizations and were therefore invited to evaluate a decision matrix containing five travel destinations ( $\mathrm{A}$ to E) based on eight different criteria, namely: (i) rating of the hotel, (which is the rating of a hotel ranging from 1, worst, to 5, best); (ii) distance in hours from the destination; (iii) number of days on the trip; (iv) price of accommodation and airfare (in US \$); (v) quantity and diversity of shopping locations (ranging from 1, worst, to 10, best); (vi) quantity and diversity of cultural attractions (ranging from 1, worst, to 10, best); (vii) presence of a natural landscape (ranging from 1, worst, to 10, best); and (viii) security, if it is safe in terms of health conditions, violence or terrorism (ranging from 1, most insecure to 10, most secure). The decision matrix can be seen in Table 1 and the volunteers' preference vectors, which were elicited using the Rank Order Centroid (ROC) method, are shown in Table 2.

Table 1: Decision matrix

\begin{tabular}{|c|c|c|c|c|c|c|c|c|}
\hline & 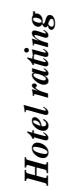 & 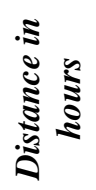 & 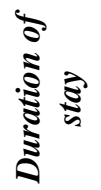 & $\tilde{\delta}$ & $\frac{\mathfrak{Z}}{\frac{2}{5}}$ & 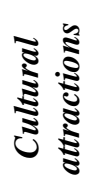 & 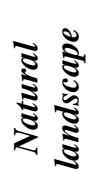 & స్తુ \\
\hline Destination A & 5 & $2.5 \mathrm{~h}$ & 4 & 2839.68 & 5 & 3 & 9 & 8 \\
\hline Destination B & 3.5 & $12 \mathrm{~h}$ & 6 & 3700.00 & 9 & 7 & 3 & 6 \\
\hline Destination C & 2.5 & $4 \mathrm{~h}$ & 5 & 2683.00 & 4 & 5 & 7 & 7.5 \\
\hline Destination D & 3 & $13 \mathrm{~h}$ & 7 & 4150.00 & 6 & 9 & 6 & 7 \\
\hline Destination E & 4 & $18 \mathrm{~h}$ & 9 & 4500.00 & 3 & 8 & 5 & 4 \\
\hline
\end{tabular}


Table 2: Weight vectors of participants

\begin{tabular}{|c|c|c|c|c|c|c|c|c|}
\hline & 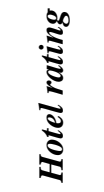 & 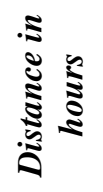 & 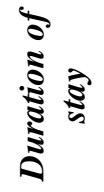 & $\vec{s}$ & 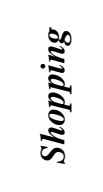 & 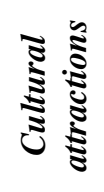 & 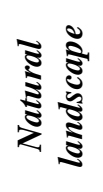 & 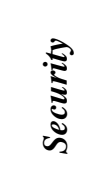 \\
\hline 1 & 0.079 & 0.016 & 0.054 & 0.152 & 0.111 & 0.340 & 0.033 & 0.215 \\
\hline 2 & 0.079 & 0.033 & 0.054 & 0.215 & 0.152 & 0.111 & 0.016 & 0.340 \\
\hline 3 & 0.152 & 0.340 & 0.079 & 0.215 & 0.054 & 0.033 & 0.111 & 0.016 \\
\hline 4 & 0.111 & 0.033 & 0.215 & 0.054 & 0.152 & 0.340 & 0.079 & 0.016 \\
\hline 5 & 0.054 & 0.016 & 0.340 & 0.215 & 0.079 & 0.152 & 0.111 & 0.033 \\
\hline 6 & 0.054 & 0.016 & 0.033 & 0.111 & 0.079 & 0.340 & 0.215 & 0.152 \\
\hline 7 & 0.215 & 0.079 & 0.054 & 0.152 & 0.016 & 0.033 & 0.340 & 0.111 \\
\hline 8 & 0.152 & 0.016 & 0.215 & 0.111 & 0.054 & 0.340 & 0.079 & 0.033 \\
\hline 9 & 0.016 & 0.111 & 0.079 & 0.054 & 0.152 & 0.340 & 0.215 & 0.033 \\
\hline 10 & 0.152 & 0.054 & 0.111 & 0.215 & 0.033 & 0.079 & 0.340 & 0.016 \\
\hline 11 & 0.152 & 0.054 & 0.215 & 0.340 & 0.016 & 0.033 & 0.111 & 0.079 \\
\hline 12 & 0.054 & 0.033 & 0.111 & 0.152 & 0.016 & 0.079 & 0.340 & 0.215 \\
\hline 13 & 0.111 & 0.054 & 0.152 & 0.079 & 0.016 & 0.340 & 0.033 & 0.215 \\
\hline 14 & 0.079 & 0.016 & 0.215 & 0.152 & 0.054 & 0.340 & 0.033 & 0.111 \\
\hline 15 & 0.079 & 0.016 & 0.215 & 0.152 & 0.033 & 0.340 & 0.111 & 0.054 \\
\hline 16 & 0.079 & 0.016 & 0.152 & 0.111 & 0.033 & 0.340 & 0.215 & 0.054 \\
\hline 17 & 0.111 & 0.016 & 0.054 & 0.340 & 0.079 & 0.152 & 0.033 & 0.215 \\
\hline 18 & 0.215 & 0.016 & 0.054 & 0.152 & 0.033 & 0.079 & 0.340 & 0.111 \\
\hline 19 & 0.152 & 0.016 & 0.079 & 0.215 & 0.340 & 0.054 & 0.033 & 0.111 \\
\hline 20 & 0.340 & 0.016 & 0.215 & 0.152 & 0.111 & 0.079 & 0.033 & 0.054 \\
\hline
\end{tabular}

The premise for assessing the adherence of the mathematical models of the Phi function with Prospect Theory is that suggested by Yoon and Hwang (1995) for which the adherence of the mathematical model is "how well a method predicts decisions made without any assistance regardless of judgments used to fit the model”. Consequently, criteria for evaluating the performance of the different models were established: (i) the number of correct answers in the first position of the classification of alternatives; and (ii) the number of correct answers for any position in the classification of alternatives. The higher the value in the criteria, the greater the adherence of the models to the decision maker's cognitive process, as described by Prospect Theory.

For the calculation of the first criterion, the count of the times in which the first position in the classification of the method coincided with that of the decision maker was used, remembering that in the experiment in Leoneti (2016) the decision makers evaluated the decision matrix and ordered the alternatives without the aid of any decision support method. To calculate the second criterion, how many positions coincided between the two classifications, whatever they were in the respective classifications, were counted.

\section{RESULTS AND DISCUSSION}


INDEPENDENT JOURNAL OF MANAGEMENT \& PRODUCTION (IJM\&P)

http://www.ijmp.jor.br

v. 12, n. 7, September-October 2021

ISSN: 2236-269X

DOI: 10.14807/ijmp.v12i7.1468

The data from the experiment presented in Leoneti (2016) were inserted in the electronic spreadsheets containing the mathematical models, which generated the data that were evaluated comparatively based on the adopted criteria, which can be seen in Table 3. Note that the differences between the values for the original TODIM method presented in this table from those in Leoneti (2016), are due to the fact that here the value for parameter $\theta$ was 2.25, for comparison with the other models available in the literature, while in Leoneti (2016) the value of $\theta$ was equal to 10 .

Table 3: Values determined for the evaluation criteria

\begin{tabular}{|c|c|c|c|c|c|c|}
\hline & 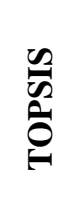 & 总 & 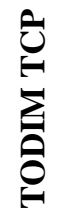 & 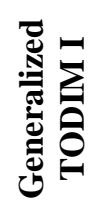 & 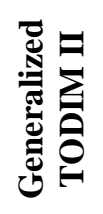 & 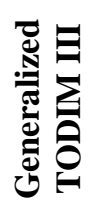 \\
\hline First position correct answers & 15 & 6 & 4 & 10 & 8 & 8 \\
\hline Correct answers for some position & 52 & 20 & 17 & 27 & 23 & 21 \\
\hline
\end{tabular}

The highest value found for criteria were identified for the TOPSIS method, which is not based on Prospect Theory. A possible explanation for this better performance is that the procedure of pairwise comparison in the TOPSIS method occurs only between the alternatives and the ideal alternative, reducing the chance of incorporating irrelevant values into the analysis, for example, the paired comparison between the worst ranked alternatives.

Regarding the TODIM method, all its variations that aimed at a greater adherence to Prospect Theory, with the exception of that proposed in Gomes and González (2012), provided higher success rates than in the original version of the TODIM method, which corroborates this approach being a path to be followed for a better use of Prospect Theory within the context of multicriteria decision making. It is worth mentioning the variation of the TODIM method proposed by Lourenzutti and Krohling (2013), which achieved the highest number of correct answers in the first position and the highest number of correct answers in any position compared to the other versions of the TODIM method, including its original version. However, it was expected that the use of Prospect Theory's rationality would provide better rates than those presented by the TOPSIS method, which is not based on a specific theory of judgment and decision.

In this sense, attention can be drawn to the fact that the Phi function modeled by Llamazares (2018), even though being that identified by the author as the most adherent to the value function proposed by Tversky and Kahneman (1992), has not achieved values higher than TOPSIS for any of the criteria. This could indicate the need to review the structure of the 
DOI: 10.14807/ijmp.v12i7.1468

Tversky and Kahneman (1992) own value function for the context of multicriteria decision making, as their mathematical model did not provide results adherent to the theory, based on the empirical data found.

In essence, the research presented in this article has provided new insights on the adherence of Prospect Theory to the structure of the TODIM method and therefore over previous works of Gomes and González (2012), Lourenzutti and Krohling (2013), Lee and Shih (2016), and Llamazares (2018).

\section{CONCLUSION}

The TODIM method proposes the use of the most complete theory of rational choice, which is based on Prospect Theory. It should be noted that the modeling of the method is relatively simple, which allows its programming and manipulation without many difficulties in a spreadsheet environment.

However, in its comparative analysis with a similar method in terms of simplicity, it is noticed that the different variations of the TODIM method regarding the incorporation of Prospect Theory's rationality within the context of multicriteria decision making, do not yet bring the benefits of a theory already consolidated for the context of decision-making aid. On the other hand, it is noted that most variations of the TODIM method presented in the literature seek to provide greater adherence to that theory.

Thus, it is suggested that further studies be conducted to improve Prospect Theory's adherence within the structure of the TODIM method, so that the benefits of a consolidated theory of decision lead to better results from the perspective of the method's prediction, considering the cognition of the decision makers' regarding the criteria being considered. Due to the increasing importance of Multicriteria Decision Aid in management and production decision-making, results that contribute to improve the foundations of well-established decision aid tools such as the TODIM method are useful to practitioners as well as researchers.

\section{ACKNOWLEDGEMENTS}

The authors would like to thank FAPESP and CNPq for their support to projects no. 2016 / 03722-5 and no. 306562 / 2017-0, respectively.

\section{REFERENCES}

Benjamin, D. J., Fontana, M. A., \& Kimball, M. S. (2020). Reconsidering Risk Aversion. NBER Working Paper No. 28007. doi: 10.3386/w28007, https:// https://www.nber.org/system/files/working_papers/w28007/w28007.pdf, 59 pp. 
Breig, Z., \& Feldman, P. (2020). Revealing Risky Mistakes through Revisions. https://zacharybreig.com/papers/RMR.pdf, Access: 15.11.2020.

Dehdasht, G., Ferwati, M. S., Zin, R. M., \& Abidin, N. Z. (2020). A hybrid approach using entropy and TOPSIS to select key drivers for a successful and sustainable lean construction implementation. PLoS ONE, 15(2, e0228746), 1-32.

https://doi.org/10.1371/journal.pone.0228746

Eisenführ, F., Weber, M., \& Langer, T. (2010). Rational Decision Making. Berlin: Springer. 467 pp.

Gomes, L. F. A. M., \& González, X. I. (2012). Behavioral multi-criteria decision analysis: further elaborations on the TODIM method. Foundations of Computing and Decision Sciences, 37(1), 3-8.

Gomes, L. F. A. M., \& Lima, M. M. P. P. (1991). TODIM: basics and application to multicriteria ranking of projects with environmental impacts. Foundations of Computing and Decision Sciences, 16(4), 113-127.

Gomes, L. F. A. M., \& Lima, M. M. P. P. (1992). From modeling individual preferences to multicriteria ranking of discrete alternatives: a look at Prospect Theory and the additive difference model. Foundations of Computing and Decision Sciences,17(3), 171-184.

Irvanizam, I., Usman, T., Iqbal, M., Iskandar, T., \& Marzuki, M. (2020). An Extended Fuzzy TODIM Approach for Multiple-Attribute Decision-Making with Dual-Connection Numbers. Advances in Fuzzy Systems, https://doi.org/10.1155/2020/6190149

Kahneman, D., \& Tversky, A. (1979). Prospect Theory: An Analysis of Decision Under Risk. Econometrica, 47(2), 263-291.

Lee, Y. S., \& Shih, H. S. (2016). Incremental analysis for generalized TODIM. Central European Journal of Operations Research, 24(4), 901-922.

Lengwiler, Y. (2009). The origins of expected utility theory. In: Hafner, W., \& Zimmermann, H. (Eds.)., in: Vinzenz Bronzin’s Option Pricing Models, 535-545. Berlin: Springer.

Leoneti, A. B. (2016). Considerations regarding the choice of ranking multiple criteria decision making methods. Pesquisa Operacional, 36(2), 259-277.

Llamazares, B. (2018). An analysis of the generalized TODIM method. European Journal of Operational Research, 269(3), 1041-1049.

Lourenzutti, R., \& Krohling, R. A. (2013). A study of TODIM in a intuitionistic fuzzy and random environment. Expert Systems with Applications, 40(16), 6459-6468.

Lu, Z., Gao, Y., \& Zhao, W. (2020). A TODIM-based approach for environmental impact assessment of pumped hydro energy storage plant. Journal of Cleaner Production, 248(1), https://doi.org/10.1016/j.jclepro.2019.119265

Mahmudova, S. (2020). Application of the TOPSIS method to improve software efficiency and to optimize its management. Soft Computing, 24, 697-708.

https://doi.org/10.1007/s00500-019-04549-4

Majumder, P., Biswas, P., \& Majumder, S. (2020). Application of New TOPSIS Approach to Identify the Most Significant Risk Factor and Continuous Monitoring of Death of COVID19. Electronic Journal of General Medicine, 17(6, em234), 1-12. https://doi.org/10.29333/ejgm/7904 
Mongin, P., \& Baccelli, J. (2020). Expected utility theory, Jeffrey's decision theory, and the paradoxes. Synthese. https://doi.org/10.1007/s11229-020-02691-3

Tversky, A. (1969). Intransitivity of preferences. Psychological Review, 76(1), 31-48.

Tversky, A., \& Kahneman, D. (1992). Advances in Prospect Theory: Cumulative representation of uncertainty. Journal of Risk and Uncertainty, 5(4), 297-323.

Yoon, K., \& Hwang, C. L. (1995). Multiple Attribute Decision Making: An Introduction. Thousand Oaks: Sage Publications. 73 pp.

Zindani, D., Maity, S. R., \& Bhowmik, S. (2020). Complex interval valued intuitionistic fuzzy TODIM approach and its application to group decision making. Journal of Ambient Intelligence and Humanized Computing. https://doi.org/10.1007/s12652-020-02308-0 